LA-UR-99-9

January 1999

$$
\text { CONF-981097-- }
$$

\title{
HYDRAULIC TESTING OF ACCELERATOR-PRODUCTION-OF-TRITIUM ROD BUNDLES
}

\section{by}

Thomas L. Spatz and Donald A. Siebe

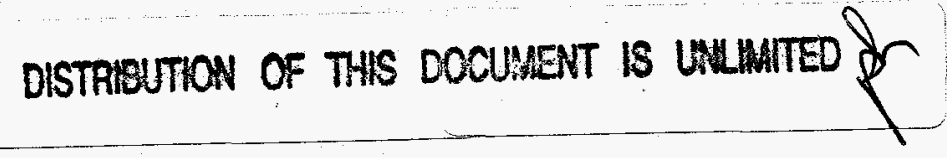

\section{MASTER}

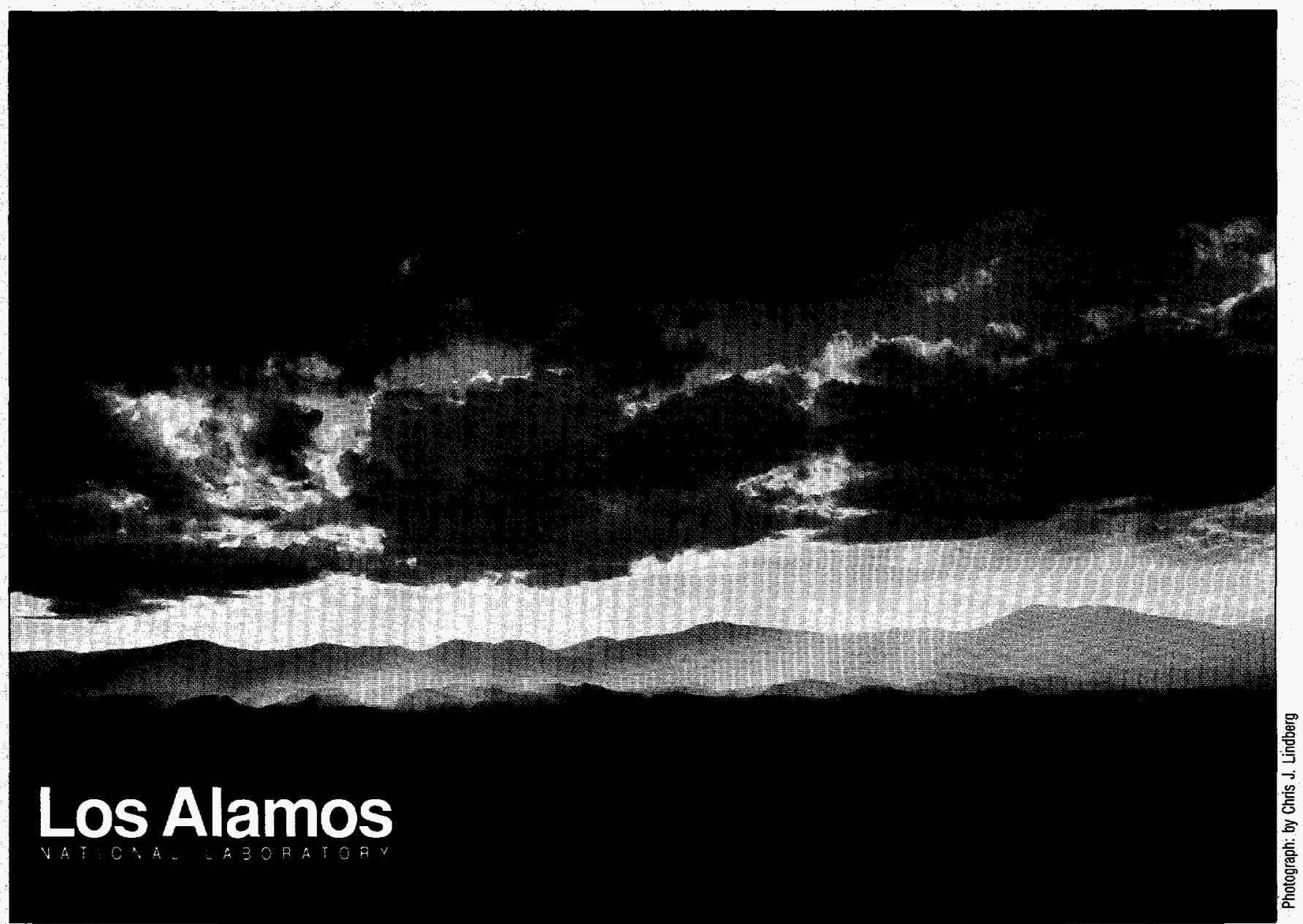

as work performed under the alspices of the U.S. Department of Energy. Los Alamos National Laboratory strongly supports academic freedom and a researchers right to publish therefore, the Laboratory as an institution does not endorse the viewpoint of a publication or guarantee its technical correctness 


\section{DISCLAIMIER}

This report was prepared as an account of work sponsored by an agency of the United States Goverameat. Neitber the United States Governiment oor any agency thereof, nor any of their employees, makes any warranty, express or implied, or assumes any legal liability or responsibility for the aceuracy, completenese, or usefulness of any information, apparatus, product, or process disclosed, or represents that its use would not infringe privately owned rights. Reference berein to any speciric commercial produch process, or service by trade mame, trademart, inanufac. turer, or otherwise does not necesuarily constitute or impiy its endorsement recom. mendation, or favoring by the United States Governmeat or any ageacy thereof. The views and opinions of authors expressed herein do not necuearily state or reflect those of the United States Government or any agency thereof. 


\section{DISCLAIMER}

Portions of this document may be illegible in electronic image products. Images are produced from the best available original document. 
Ninth International Topical Meeting on Nuclear Reactor Thermal Hydraulics (NURETH-9) San Francisco, California, October 3 - 8, 1999.

\title{
HYDRAULIC TESTING OF THE ACCELERATOR-PRODUCTION-OF- TRITIUM ROD BUNDLE
}

\author{
Thomas L. Spatz ${ }^{1}$ and Donald A. Siebe ${ }^{2}$ \\ ${ }^{1}$ Engineering Sciences and Applications Division \\ ${ }^{2}$ Technology and Safety Assessment Division \\ Los Alamos National Laboratory \\ Los Alamos, New Mexico 87545 USA \\ email: spatz@lanl.gov, dsiebe@lanl.gov
}

\section{KEY WORDS}

Hydraulics, rod bundles, pressure drop.

\begin{abstract}
Hydraulic tests have been performed on small pitch-to-diameter-ratio rod bundles using light water $(1.7<\mathrm{P} / \mathrm{D}<1.17$, and $\mathrm{d}=3.175 \mathrm{~mm})$. Flows cover the range from greater-than-nominal Reynolds numbers (fully turbulent) to low-speed laminar flows. Differential pressure measurements were made across the support plates holding the rod bundles, across the rod bundles, and across the entire assembly. Flow rates, temperatures, and gauge pressures also were measured.
\end{abstract}

The data from these hydraulic tests have been compared to correlating literature for tightly pitched rod bundles. The prototypic geometry of these tests did not compare directly to any geometry found in the literature because of the variety of subchannels along the outer wall of the rod bundle. Under that constraint, there was excellent comparison of the rodbundle friction factor with those factors given in the literature. The results show a large range of the Reynolds number over which the flow is in transition from laminar to turbulent (e.g., $580<\operatorname{Re}_{\mathrm{Tr}}<13,000$ ). Also presented is the comparison of the overall rung pressure drop to a solution based on hydraulic-resistance handbook calculations.

\section{INTRODUCTION}

One design option for the neutron source for the Accelerator Production of Tritium (APT) consists of tightly packed triangular-pitch bundles of tungsten rods. The target details given in this paper were the baseline values from early 1996 when this test was designed. The entire APT target in this design consisted of 10 ladders, where each rung of a ladder contained one bundle of tungsten rods. The rod bundles are housed within stainless-steal outer sleeves (tubes), with the triangular-pitch rod spacing maintained by support plates at each end of the rods. The rod bundles are cooled by heavy water that runs down one side of the ladder, through the rungs of the ladder (housing the rod bundles), and up the other side of the ladder. This design alternative has four different geometries of ladders: ladders 1 through 4,5 through 6,7 through 8 , and 9 through 10 . A general description of the target-blanket design and function can be found in the "Conceptual Design Report" (Lisowski, 1997).

Two bundle sizes were tested: one representing a rod bundle from ladder 2 , where the power density is expected to be the greatest, and one representing a rod bundle from ladder 10, where the power density is the lowest. Table 1 gives the nominal values for the bundle flow rates, velocities, and Reynolds numbers for the two rod bundles tested. 
Table 1. Bundle geometry and flow specifications.

\begin{tabular}{|c|c|c|}
\hline Specifications & Ladder-2 Bundles & Ladder-10 Bundles \\
\hline Number of large rods & 73 & 151 \\
\hline Number of small rods & 12 & 12 \\
\hline Large-rod diameter $(\mathrm{cm})$ & 0.3175 & 0.4775 \\
\hline Small-rod diameter $(\mathrm{cm})$ & 0.2362 & 0.2362 \\
\hline Bundle o.d. $(\mathrm{cm})$ & 3.810 & 7.145 \\
\hline Hydraulic diameter $(\mathrm{cm})$ & 0.1735 & 0.1994 \\
\hline Bundle flow rate $(\mathrm{kg} / \mathrm{s})$ & 1.99 & 1.65 \\
\hline Bundle average velocity $(\mathrm{m} / \mathrm{s})$ & 5.08 & 1.55 \\
\hline Bundle Re number & 17,300 & 4900 \\
\hline
\end{tabular}

The pressure drop (nondimensionalized) vs the Reynolds number was measured for the above cases at Reynolds numbers ranging from 0 to 1.2 times the design Reynolds number. The Reynolds number was varied by changing either the flow rate or the temperature of the water to between $20^{\circ} \mathrm{C}$ and $90^{\circ} \mathrm{C}$. Light water was used in these experiments, which did not measure heat transfer. This was purely a hydraulics test, even though the water was heated to vary the Reynolds number. There was no heating of the rod bundle.

Two different design options for the ladder- 2 rod bundle were tested: one with "fillers" on the inside of the outer sleeve and one without fillers. The fillers are used to simulate a section of a rod at the outer sleeve so that a larger flow channel does not exist between the inner surface of the tube and the outer ring of rods than exists in the center of the bundle. The outer sleeve with the fillers is shown in Fig. 1. The hope is to have a flow distribution that is evenly distributed radially without the flow preferentially flowing along the outer wall, where the flow area is larger for the rod bundle without fillers. This test could measure only the pressure drop difference caused by the addition of fillers. Information on flow distribution was not obtained from this test.
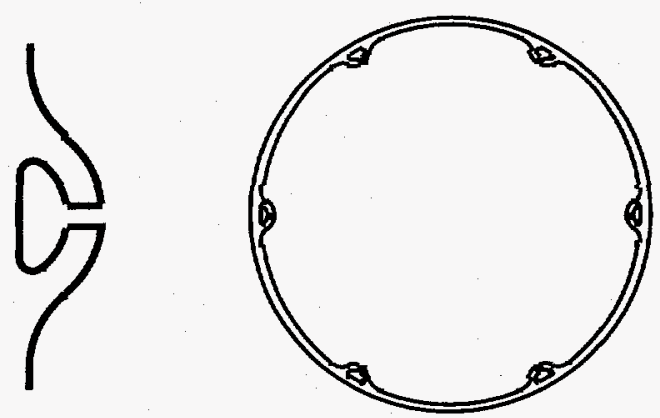

Fig. 1 Outer sleeve with fillers. 
This paper describes the objectives, apparatus, test matrix, test results, comparison between calculations and test results, and conclusions for hydraulic testing of a single rod bundle. The objectives of this series of tests are summarized below.

- The primary objective of the out-of-beam single bundle tests was to obtain pressure drop data relating to the Reynolds number over the range of $0 \leq \mathrm{Re} / \mathrm{Re}_{\text {Design }} \leq 1.2$.

- This test was also to measure the pressure drop difference caused by the addition of fillers.

The test program was successful in meeting these objectives. The sections that follow describe the test results and comparisons to calculations.

\section{APPARATUS}

A schematic diagram of the test loop is given in Fig. 2. The test loop consists of a water reservoir with a heating loop, the rod-bundle subassembly flow loop, and a bypass loop. A 0-to-40-gpm (0-to- $2.47-\mathrm{kg} / \mathrm{s})$ flow meter is attached to the rod-bundle subassembly flow loop to measure the flow rate through the rod bundle independent of any bypass flow. A 25-hp pump, capable of flow rates of $600 \mathrm{gpm}(37 \mathrm{~kg} / \mathrm{s})$ at low head losses, drives the fluid.

The rod-bundle subassembly consists of a manifold that can allow for the attachment of either a ladder- 2 or a ladder-10 rod bundle. Figure 3 is a schematic of the rod-bundle subassembly. Only one rod bundle was tested at a time. The second rod bundle was removed and the flanges capped. Absolute pressure transducers measured the pressure in the inlet and outlet manifold, which are adjacent to the rod bundle. Another absolute pressure transducer measured the pressure at the center of the rod bundle to verify the differential pressure measurements. Differential pressure transducers measured the pressure drop across each support plate and from each support plate to the center of the rod bundle for a total of four differential pressure measurements. The pressure measurement at the entrance to the rod bundle, just upstream of the support plate, can be averaged over two locations $180^{\circ}$ apart. These two measurements at the same location are performed to compensate for the short entrance length between the downcomer and the rod-bundle support plate. Thermocouples were used to measure the fluid temperature in the downcomer and riser.

\section{METHOD OF DATA ANALYSIS}

This section will focus on the analytical solution used to compare the calculated pressure drop with the experimental results. Each rod-bundle assembly consists of a front support plate, the rod bundle, and a rear support plate. The analysis used for each of these sections will be given separately.

\subsection{Inlet Support Plate}

The inlet support plate is a $0.00305-\mathrm{m}(0.120$-in.)-thick disc that holds the rods in place. The rods are in a triangular array, and the support plate has a hole for fluid flow at the center of every triangulated area. For this analysis, the holes will be characterized as thick-edged orifices. An equation for flow resistance for a thick-edged orifice in a transition region from The Handbook of Hydraulic Resistance (Idelchik, 1994) was used for the support plates. Figure 4 and Eq. 1 show the flow resistance for a thick-edged orifice from Idelchik (1994). 


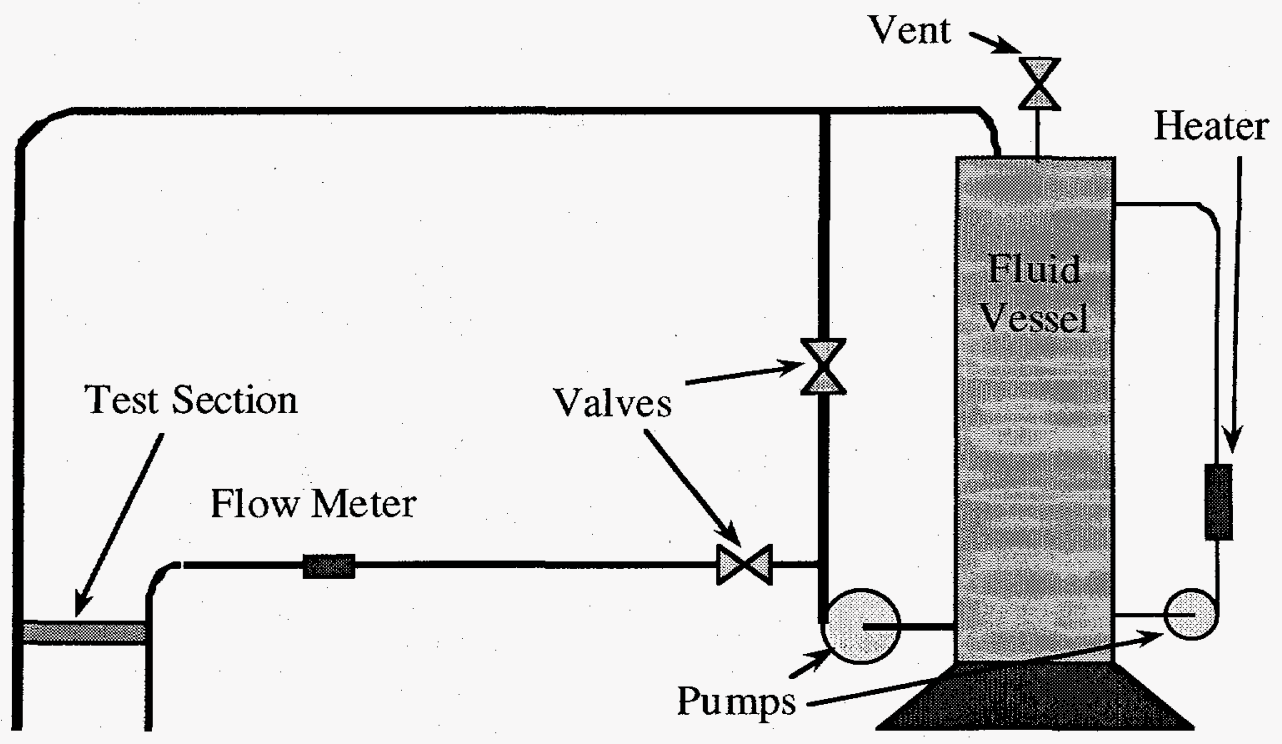

Fig. 2 Flow loop schematic diagram.

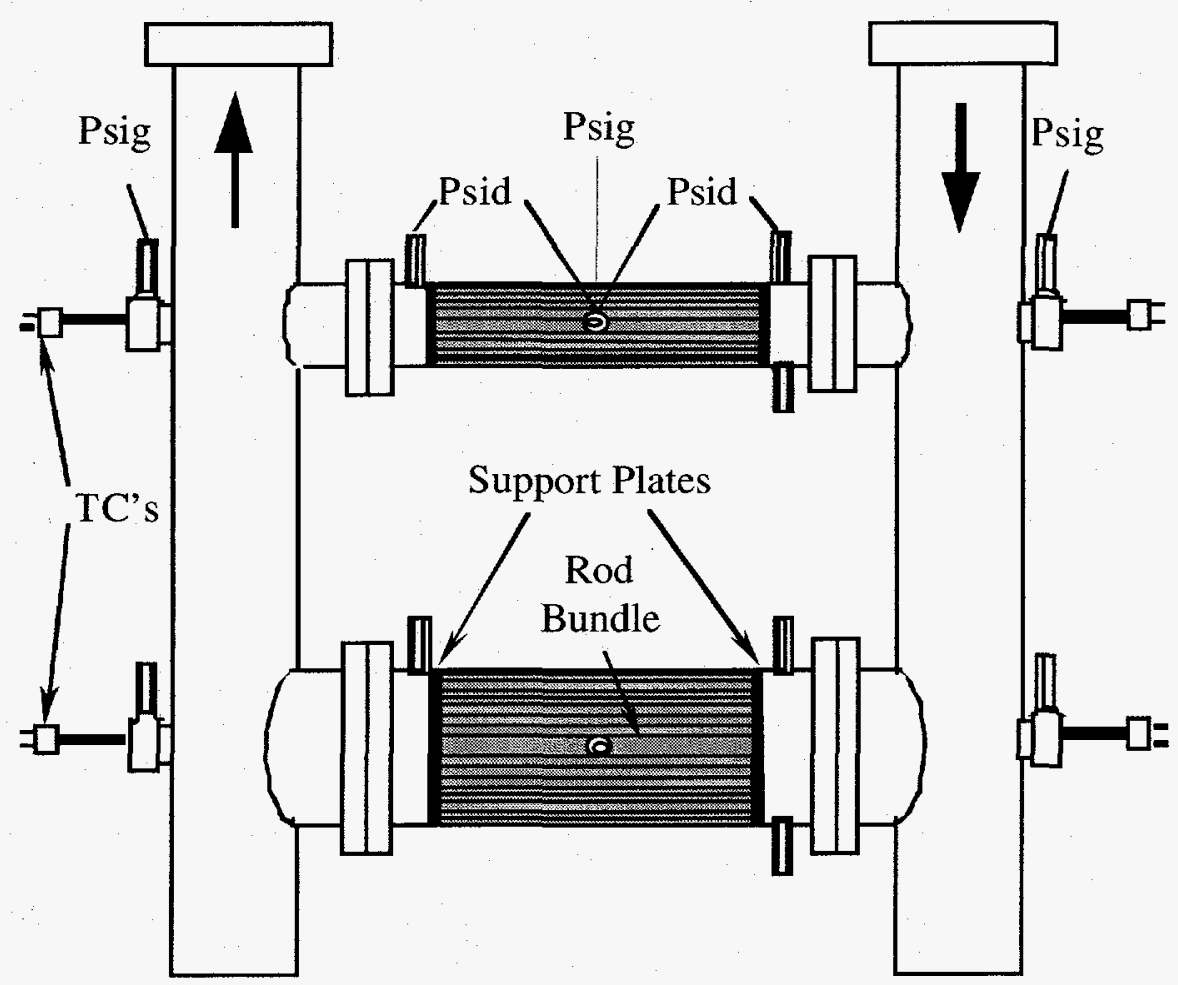

Fig. 3 Rod-bundle subassembly schematic. 


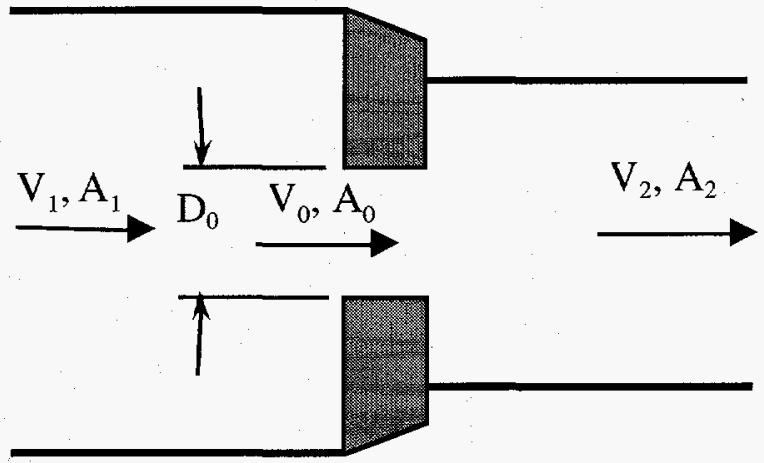

Fig. 4 Schematic of a thick-edged orifice.

$$
K=0.5\left(1-\frac{A_{0}}{A_{1}}\right)^{0.75}+\left(1-\frac{A_{0}}{A_{2}}\right)^{2}+\tau\left(1-\frac{A_{0}}{A_{2}}\right)\left(1-\frac{A_{0}}{A_{1}}\right)^{0.375}+f \frac{l}{D_{h}},
$$

where $\tau$ as a function of $l / D$ is given by Eq. 2 (Idelchik, 1994) as

$$
\tau=\left(2.4-\frac{l}{D_{h}}\right) * 10\left(0.25+\frac{0.535\left(\frac{l}{D_{h}}\right)^{8}}{\left(0.05+\left(\frac{l}{D_{h}}\right)^{8}\right)}\right) .
$$

The $K$ defined in Eq. 1 is based on the average velocity through the hole $\left(\mathrm{V}_{0}\right)$. It is valid for $l / D_{h}>0.015$ and $\operatorname{Re}>10^{4}$, where $\operatorname{Re}$ is the orifice Reynolds number. The first and second terms of Eq. 1 are the terms typically used for sudden contraction and sudden expansion, respectively. The third term is a correction term to account for a lack of fully developed flow through the orifice plate. The fourth term is a typical friction factor $x V D$ term.

Although the geometry of the support plates is similar to the geometry upon which Eq. 1 is based, there is one complication. The rods partially obstruct the flow holes in the support plates, making a plane with a flow area smaller than the flow area of the holes through the plate. To account for this second contraction, the first term in the previous equation will be repeated using the areas of the support plate and the plate-rod interface area. Figure 5 and Eq. 3 give the actual support-plate diagram and form-loss equation.

$$
\begin{gathered}
K=0.5\left(1-\frac{A_{0}}{A_{1}}\right)^{0.75}+0.5\left(1-\frac{A_{0^{\prime}}}{A_{0}}\right)^{0.75}\left(\frac{A_{0}}{A_{0^{\prime}}}\right)^{2}+\left(1-\frac{A_{0^{\prime}}}{A_{2}}\right)^{2}\left(\frac{A_{0}}{A_{0^{\prime}}}\right)^{2} \\
+\tau\left(1-\frac{A_{0}}{A_{2}}\right)\left(1-\frac{A_{0}}{A_{1}}\right)^{0.375}+f \frac{l}{D_{h}}
\end{gathered}
$$




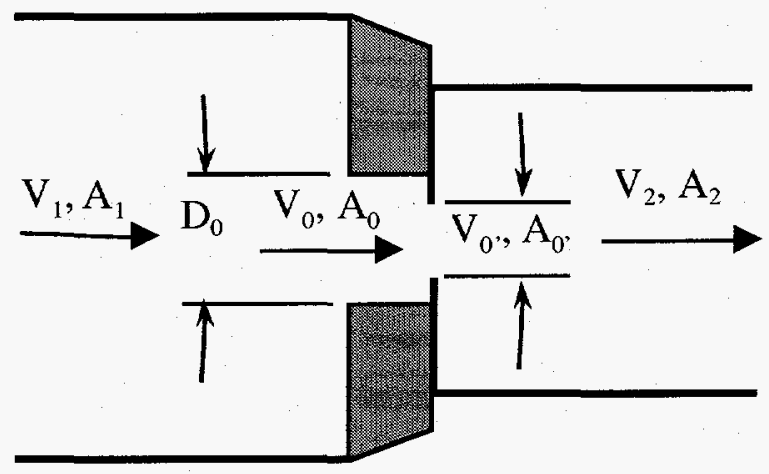

Fig. 5 Schematic of a support-plate orifice.

The third term in Eq. 3, which accounts for the sudden expansion, now expands from the plate-rod interface area to the rod-bundle area. The second and third terms are multiplied by the area ratio squared to base each term on the support-plate hole velocity. The last two terms are an order of magnitude smaller than the first term, and they will remain unchanged from the referenced equation.

The $K$ defined in Eq. 3 is based on the average velocity through the hole $\left(\mathrm{V}_{0}\right)$. The support-plate holes will be assumed to be smooth pipes in the turbulent regime. Equation 4 will be used for the turbulent friction factor for smooth pipes. This is a common textbook approximation for a hydraulically smooth friction factor.

$$
f=\frac{1.02}{\left(\log _{10} \operatorname{Re}\right)^{2.5}}
$$

Table 2 gives the inlet support-plate areas for all of the geometries tested.

The majority of experimental data collected in this study was for $\operatorname{Re}<10^{4}$. Idelchik (1994) uses a multiplier to the form-loss coefficient for $\operatorname{Re}>10^{4}$ and then adds another term to that product to obtain the form-loss coefficient over the range $30<\operatorname{Re}<10^{4}$. The form-loss coefficient over this range of Reynolds numbers is given as Eq. 5:

$$
K=K_{\phi}+\beta_{0, \operatorname{Re}} K_{0(\operatorname{Re}>10000)}
$$

Table 2. Inlet support-plate specifications.

\begin{tabular}{|c|c|c|l|}
\hline Term & Ladder 2 & Ladder 2 & Ladder 10 \\
\hline$A_{l}\left(\mathrm{~m}^{2}\right)$ & 0.001036 & 0.001036 & 0.003776 \\
\hline$A_{0}\left(\mathrm{~m}^{2}\right)$ & 0.0003272 & 0.0003272 & 0.0006545 \\
\hline$A_{0}\left(\mathrm{~m}^{2}\right)$ & 0.0002385 & 0.0002385 & 0.0004912 \\
\hline$A_{2}\left(\mathrm{~m}^{2}\right)$ & 0.0004056 & 0.0003873 & 0.0009772 \\
\hline$W D$ & 1.9355 & 1.9355 & 1.9355 \\
\hline Pitch/D & 1.168 & 1.168 & 1.064 \\
\hline
\end{tabular}


The term $\mathrm{K}_{0(\mathrm{Re}>10000)}$ is given by Eq. 3 as the fully turbulent form-loss coefficient. The term $\beta_{0, \operatorname{Re}}$ is given by Eq. 6 (Idelchik, 1994) as

$$
\beta_{0, \mathrm{Re}}=\sum_{\mathrm{i}=0}^{5} a_{i}\left(\log _{10} \mathrm{Re}\right)^{i}
$$

where $a_{0}=0.461465, a_{1}=-0.2648592, a_{2}=0.2030479, a_{3}=-0.06602521$, $\mathrm{a}_{4}=0.01325519$, and $\mathrm{a}_{5}=-0.001058041$.

The values for $K_{\phi_{-}}$were given in Diagram 4-19 in Idelchik (1994). The table values were curve fitted to use them in a spread sheet. A sixth-order polynomial was the best curve fit found, and it is given by Eq. 7:

$$
K_{\phi}=\sum_{i=0}^{6} a_{i} \frac{1}{\left(\log _{10} \operatorname{Re}\right)^{i}}
$$

where $a_{0}=0.1719, a_{1}=-4.0329, a_{2}=28.475, a_{3}=-100.8, a_{4}=275.78, a_{5}=-418.79$, and $a_{6}=248.7$.

Equations 3 through 7 will be used in the results section when comparing the pressure loss between two pressure taps from the experimental data and the analytical solution. The analysis for the pressure drop along a tightly packed triangular-array rod bundle will be given next.

\subsection{Rod Bundle}

The pressure drop through the bundle has been calculated using the friction factor correlations in Cheng and Todreas (1986) for triangular arrays. Cheng and Todreas (1986) performed a comprehensive investigation of several studies involving rod-bundle geometries. The reader is encouraged to refer to Cheng and Todreas (1986) for a detailed literature search of frictional losses in rod bundles. In this study, a series of steps based on subchannel flow splits [from Cheng and Todreas (1986)] will be followed to yield overall bundle friction-factor correlations for the laminar, turbulent, and transition flow regimes.

The flow in rod bundles may have a large range of Reynolds numbers over which the flow is in transition between laminar and turbulent. The flow in the small gap between rods remains laminar long after the flow down the larger gap in the triangulated area is turbulent. The bundle Reynolds numbers that bound the transition regime are functions of the pitch-to-diameter ratio and are given by Eqs. 8 and 9:

$$
\begin{aligned}
& \log _{10}\left(\frac{\operatorname{Re}_{\mathrm{bL}}}{300}\right)=1.7\left(\frac{P}{D}-1\right) \text { and } \\
& \log _{10}\left(\frac{\operatorname{Re}_{\mathrm{bT}}}{10,000}\right)=0.7\left(\frac{P}{D}-1\right),
\end{aligned}
$$


where $\mathrm{Re}_{\mathrm{bL}}$ is the laminar-transition Reynolds number and $\mathrm{Re}_{\mathrm{bT}}$ is the transition-turbulent Reynolds number. The flow is in transition for all Reynolds numbers over the range $\operatorname{Re}_{\mathrm{bL}}$ $<\operatorname{Re}<\operatorname{Re}_{\mathrm{bT}}$.

A discussion of the various subchannels in the APT rod bundle is given next. The rod bundles in Cheng and Todreas (1986) are triangular-pitch bundles in a hexagonal housing. In this case, there are three types of subchannels: an internal subchannel, an edge subchannel, and a corner subchannel. The APT rod bundle is a triangular-pitch bundle in a cylindrical housing with smaller rods around the edge to fill in the larger flow channels caused by the cylindrical housing. There are six subchannel types for the ladder- 2 rod bundle and seven subchannel types for the ladder-10 rod bundle. Figures 6 and 7 show schematic diagrams of the subchannels for the ladder- 2 and ladder- 10 rod bundles, respectively. The bundles are symmetric over $60^{\circ}$ pie sections. All dimensions shown in Figs. 6 and 7 are in millimeters.

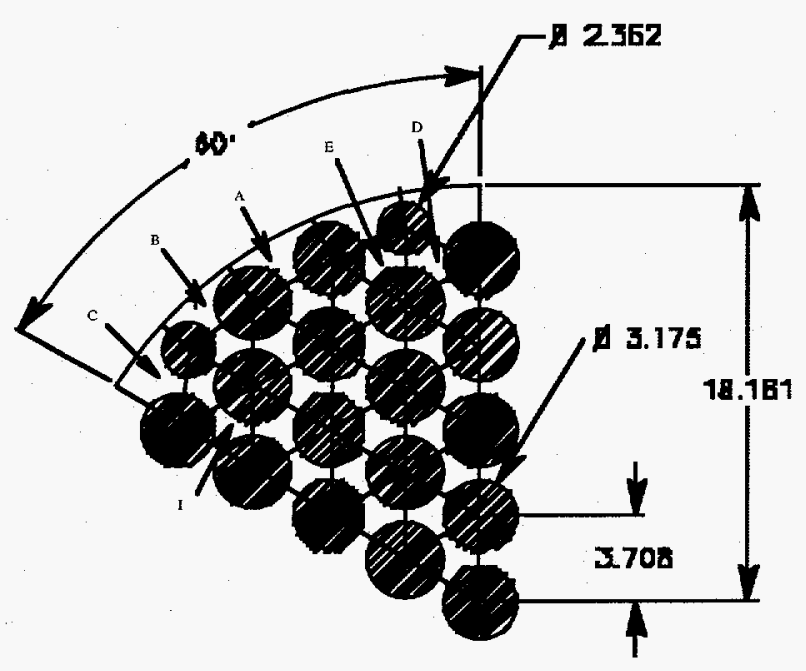

Fig. 6 Bundle-2 pie section showing subchannel identification.

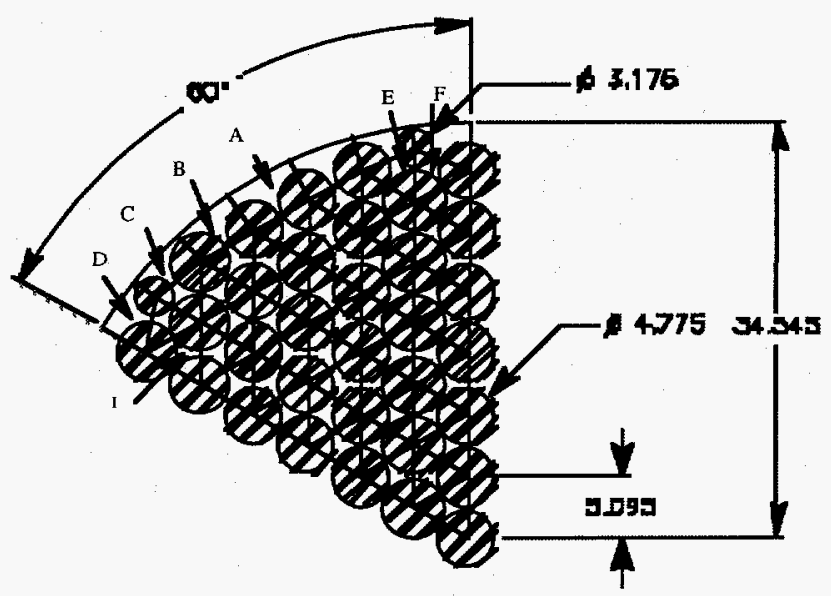

Fig. 7 Bundle-10 pie section showing subchannel identification. 
To determine the overall bundle properly, both for laminar and turbulent coefficients of friction, a subchannel analysis must be performed. This involves determining the flow area, hydraulic diameter, laminar coefficient of friction, turbulent coefficient of friction, and flow split parameter for every subchannel. The unique geometry of the rod bundle in this experiment introduces some error into the analytical solution of the rod-bundle friction factor. As was mentioned in the previous paragraph, the rod bundles used in Cheng and Todreas (1986) are enclosed in a hexagonal housing. Correlations are given in Cheng and Todreas (1986) for the laminar and turbulent coefficients of friction for internal, corner, and edge subchannels over two ranges of pitch-to-diameter ratios. These correlations are based on experimental data of rod bundles in hexagonal housings. The internal subchannels of Cheng and Todreas (1986) are identical to the subchannels in Figs. 5 and 6 with the letter "T" in the channel. The corner subchannels in Cheng and Todreas (1986) are not similar to any subchannel in this study, and the corner subchannel correlations will not be used. The edge subchannels of Cheng and Todreas (1986) are channels bounded by two identical diameter rods and a straight flat wall. The pitch for an edge subchannel is defined as the distance from the wall to the rod plus the diameter of the rod. The internal and edge subchannel correlations will be used in the analysis of the bundles in this study, even though the subchannels in this study are not identical to the referenced subchannels. The uniqueness of these dissimilar subchannels will be discussed next.

Two internal subchannels in the APT rod bundles have two different rod diameters. All of the edge subchannels have curved outer surfaces, and two of them have different rod diameters. These subchannels introduce uncertainties in evaluating the pitch-to-diameter ratio. There are more dissimilar pitches with respect to the smaller rods than there are with respect to the larger rods within the same internal subchannel. The edge subchannels have three different pitches associated with them. There is one pitch between the rods and one from each rod to the curved surface.

There are three sides in a triangular-pitch array subchannel from which a pitch-to-diameter ratio can be defined. For any one side of the triangle having two different diameter rods, the average rod diameter was used to evaluate the pitch-to-diameter ratio. The average of the three individual pitch-to-diameter ratios, or wall-pitch-to-diameter ratios, was used as the subchannel pitch-to-diameter ratio. Table 3 summarizes the subchannel geometries for the bundles in Figs. 6 and 7.

The subchannel coefficients of friction given in Cheng and Todreas (1986) are experimentally derived polynomials with different constants for internal and external subchannels, turbulent and laminar flows, and two ranges of pitch-to-diameter ratios. The subchannel coefficients of friction polynomial are given as Eq. 10:

$$
C_{f \mathrm{~L}, \mathrm{~T}}=c 1+c 2\left(\frac{P}{D}-1\right)+c 3\left(\frac{P}{D}-1\right)^{2}
$$

The constants $c 1, c 2$, and $c 3$ are given in Table 4 (Cheng and Todreas, 1986).

The coefficients of friction for every subchannel are approximated from Eq. 10 and Table 4. The overall bundle coefficients of friction and flow split parameters can now be evaluated. The flow split parameter is defined as the ratio of the velocity in a particular subchannel to the overall bundle velocity $(X i=V i / V b)$. The equations used to evaluate the 
Table 3. Subchannel specifications.

\begin{tabular}{|c|c|c|c|c|c|c|}
\hline Ladder & Subchannel & $\begin{array}{c}\text { Number } \\
\text { per } \\
\text { Bundle }\end{array}$ & $\begin{array}{c}\mathrm{D}_{\mathbf{h}} \\
(\mathbf{i n} .)\end{array}$ & $\begin{array}{c}\text { Flow Area } \\
\left(\text { in. }^{2}\right) * \mathbf{1 0}^{-3}\end{array}$ & $\begin{array}{c}\text { Fraction of } \\
\text { Flow Area } \\
(S)\end{array}$ & $P / D(W / D)$ \\
\hline 2 & $\mathrm{I}$ & 114 & 0.06238 & 3.06208 & 0.53468 & 1.168 \\
\hline 2 & $\mathrm{~A}$ & 6 & 0.084317 & 8.144 & 0.07485 & 1.176 \\
\hline 2 & $\mathrm{~B}$ & 12 & 0.057772 & 4.65219 & 0.08551 & 1.164 \\
\hline 2 & $\mathrm{C}$ & 12 & 0.105041 & 8.21372 & 0.15097 & 1.3396 \\
\hline 2 & $\mathrm{D}$ & 12 & 0.063665 & 2.83224 & 0.05206 & 1.2107 \\
\hline 2 & $\mathrm{E}$ & 12 & 0.034277 & 1.5501 & 0.02849 & 1.1783 \\
\hline 2 & $\mathrm{Bundle}$ & & 0.068588 & 652.870 & 1 & 1.168 \\
\hline 10 & $\mathrm{I}$ & 258 & 0.047984 & 3.54255 & 0.60286 & 1.067 \\
\hline 10 & $\mathrm{~A}$ & 6 & 0.127585 & 17.0795 & 0.06759 & 1.2177 \\
\hline 10 & $\mathrm{~B}$ & 12 & 0.103704 & 13.7195 & 0.10859 & 1.1527 \\
\hline 10 & $\mathrm{C}$ & 12 & 0.122026 & 8.278 & 0.06552 & 1.1693 \\
\hline 10 & $\mathrm{D}$ & 12 & 0.112755 & 12.0388 & 0.09529 & 1.2293 \\
\hline 10 & $\mathrm{E}$ & 12 & 0.060836 & 3.92493 & 0.03107 & 1.1205 \\
\hline 10 & $\mathrm{~F}$ & 12 & 0.061055 & 3.93991 & 0.03118 & 1.1212 \\
\hline 10 & Bundle & & 0.078504 & 1516.06 & 1 & 1.067 \\
\hline
\end{tabular}

bundle average coefficient of friction and flow split parameters are derived in Cheng and Todreas (1986). The flow split parameters are evaluated from Eqs. 11 and 12. The summation of 6 terms is for ladder-2 subchannels; the summation of 7 terms is for ladder10 subchannels:

Table 4. Constants for Eq. 10.

\begin{tabular}{|c|l|l|c|c|c|}
\hline $\begin{array}{c}\text { Pitch/ } \\
\text { Diameter }\end{array}$ & $\begin{array}{c}\text { Flow } \\
\text { Regime }\end{array}$ & $\begin{array}{c}\text { Subchannel } \\
\text { Type }\end{array}$ & $\boldsymbol{c 1}$ & $\boldsymbol{c 2}$ & $\boldsymbol{c 3}$ \\
\hline $1 \leq P / D \leq 1.1$ & Laminar & Interior & 26.00 & 888.2 & -3334 \\
\hline & & Edge & 26.18 & 554.5 & -1480 \\
\hline & Turbulent & Interior & 0.09378 & 1.398 & -8.664 \\
\hline & & Edge & 0.09377 & 0.8732 & -3.341 \\
\hline $1.1 \leq P / D \leq 1.5$ & Laminar & Interior & 62.97 & 216.9 & -190.2 \\
\hline & & Edge & 44.40 & 256.7 & -267.6 \\
\hline & Turbulent & Interior & 0.1458 & 0.03632 & -0.03333 \\
\hline & & Edge & 0.1430 & 0.04199 & -0.04428 \\
\hline
\end{tabular}




$$
\begin{aligned}
& \sum_{i=1}^{6,7}\left(S_{i} X_{i}\right)=1 \text { and } \\
& \frac{X_{i}}{X_{j}}=\left(\frac{D_{h i}}{D_{h j}}\right)^{\frac{1+m}{2-m}}\left(\frac{C_{f j}}{C_{f i}}\right)^{\frac{1}{2-m}} .
\end{aligned}
$$

In the previous equation, " $\mathrm{m}$ " is the Reynolds number exponent for the friction factor, where $\mathrm{m}=1$ for laminar flow and $\mathrm{m}=0.18$ for turbulent flow. The bundle-average coefficients of frictions are evaluated from Eq. 13 as

$$
C_{f b}=D_{h b}\left[\sum_{i=1}^{6,7} S_{i}\left(\frac{D_{h i}}{D_{h b}}\right)^{\frac{m}{2-m}}\left(\frac{C_{f i}}{D_{h i}}\right)^{\frac{1}{m-2}}\right]^{(m-2)} .
$$

Table 5 summarizes the results for the subchannel coefficients of friction, flow split parameters, and transition Reynolds numbers. It also shows the bundle average coefficients of friction and transition Reynolds numbers. Notice that for ladder 10, the bundle-average coefficients of friction vary significantly from the internal subchannel coefficient. This will be discussed further in the results section.

The bundle average friction factors $\left(f_{\mathrm{bL}}, f_{\mathrm{bT}}\right)$ are given as Eq. 14:

$$
f_{\mathrm{bL}, \mathrm{T}}=\frac{C_{f_{\mathrm{bL}, \mathrm{T}}}}{\operatorname{Re}_{\mathrm{b}}{ }^{m}},
$$

where $m=1$ for laminar flow and $m=0.18$ for turbulent flow.

The transition friction factor $\left(f_{\mathrm{Tr}}\right)$ will be discussed next. Table 5 reveals a transition regime for ladder-2 rod bundles between Reynolds numbers of 579 and 13,110. Most of the data collected from the experiments were within this range of Reynolds numbers. Cheng and Todreas (1986) define an "intermittency factor" $(\Psi)$ that is used to yield a weighted average of the laminar and turbulent friction factors. The intermittency factor is a function of the Reynolds number and is given as Eq. 15:

$$
\Psi_{x}=\frac{\log _{10}\left(\operatorname{Re}_{\mathrm{bx}}\right)-\log _{10}\left(\mathrm{Re}_{\mathrm{bL}}\right)}{\log _{10}\left(\mathrm{Re}_{\mathrm{bT}}\right)-\log _{10}\left(\mathrm{Re}_{\mathrm{bL}}\right)}
$$

The transition friction factor then is given by Eq. 16:

$$
f_{\mathrm{b} T r}=f_{\mathrm{bL}}(1-\Psi)^{\gamma}+f_{\mathrm{bT}} \Psi^{\gamma}
$$


Table 5. Subchannel friction coefficients and Reynolds numbers.

\begin{tabular}{|c|c|c|c|c|c|c|c|}
\hline Ladder & Subchannel & $C_{f L}$ & $C_{f T}$ & $X_{L}$ & $X_{T}$ & $\mathbf{R e}_{\mathbf{L}}$ & $\mathbf{R e}_{\mathbf{T}}$ \\
\hline 2 & $\mathrm{I}$ & 94.04 & 0.1510 & 0.8072 & 1.0091 & 425 & 12,032 \\
\hline 2 & $\mathrm{~A}$ & 81.29 & 0.1490 & 1.7060 & 1.2356 & 1214 & 19,914 \\
\hline 2 & $\mathrm{~B}$ & 79.30 & 0.1487 & 0.8210 & 0.9681 & 400 & 10,690 \\
\hline 2 & $\mathrm{C}$ & 100.7 & 0.1521 & 2.1371 & 1.4086 & 1895 & 28,282 \\
\hline 2 & $\mathrm{D}$ & 100.2 & 0.1520 & 0.7889 & 1.0188 & 424 & 12,398 \\
\hline 2 & E & 95.59 & 0.1512 & 0.2398 & 0.6838 & 69.4 & 4,480 \\
\hline 2 & Bundle & 91.76 & 0.1716 & & & 579 & 13,110 \\
\hline 10 & I & 70.54 & 0.1485 & 0.4308 & 0.7901 & 103 & 6,278 \\
\hline 10 & A & 87.60 & 0.1500 & 2.4527 & 1.4813 & 1555 & 31,296 \\
\hline 10 & B & 77.36 & 0.1484 & 1.8351 & 1.3030 & 945 & 22,376 \\
\hline 10 & C & 80.18 & 0.1488 & 2.4512 & 1.4455 & 1486 & 29,209 \\
\hline 10 & D & 89.20 & 0.1503 & 1.8814 & 1.3660 & 1054 & 25,504 \\
\hline 10 & E & 86.35 & 0.1497 & 0.5658 & 0.9176 & 171 & 9,244 \\
\hline 10 & F & 86.47 & 0.1497 & 0.5690 & 0.9197 & 173 & 9,298 \\
\hline 10 & Bundle & 81.35 & 0.1729 & & & 390 & 11,140 \\
\hline
\end{tabular}

The exponent $\gamma$ is fitted from data. From their database, Cheng and Todreas (1986) calibrated $\gamma$ to be $1 / 3$, which yielded a root mean square of the prediction error of $9.3 \%$. The experimental data of this paper will be compared to the analytical transition friction factor with $\gamma=1 / 3$.

\subsection{Exit Support Plate}

The exit support plate will be analyzed with an analysis similar to that used for the front support plate. However, in this case, there are two expansions and one contraction. The defining sketch and equation are given as Fig. 8 and Eq. 17.

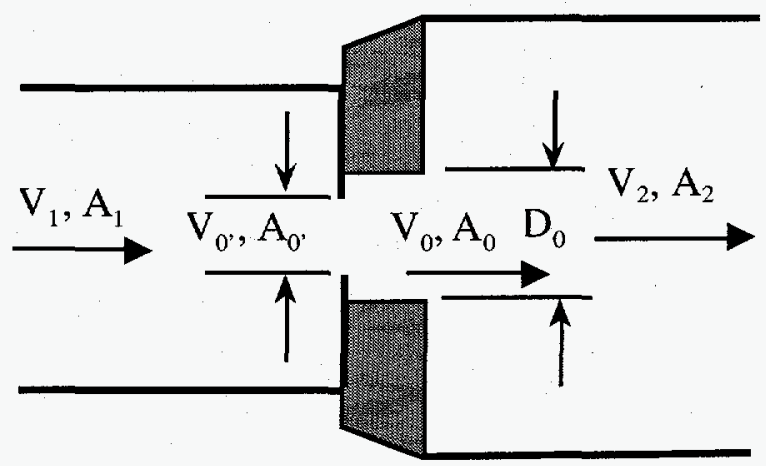

Fig. 8 Schematic of exit support plate. 


$$
\begin{gathered}
K=0.5\left(1-\frac{A_{0^{\prime}}}{A_{1}}\right)^{0.75}\left(\frac{A_{0}}{A_{0^{\prime}}}\right)^{2}+\left(1-\frac{A_{0^{\prime}}}{A_{0}}\right)^{2}\left(\frac{A_{0}}{A_{0^{\prime}}}\right)^{2}+\left(1-\frac{A_{0}}{A_{2}}\right)^{2} \\
+\tau\left(1-\frac{A_{0}}{A_{2}}\right)\left(1-\frac{A_{0}}{A_{1}}\right)^{0.375}+f \frac{l}{D_{h}}
\end{gathered}
$$

The friction factor $(f)$ for the support-plate holes was obtained from Eq. 4 and the shear coefficient $(\tau)$ from Eq. 2. Table 6 gives the areas for the exit support plate that can be inserted directly into Eq. 17.

All of the equations necessary to calculate the pressure losses along the rod-bundle assembly have been given. The following section will present the experimental data and compare that data to the analytical approach presented in the previous three sections.

\section{RESULTS}

All pressure readings, the two temperature readings, and the flow rate were recorded on the Data Acquisition System at steady-state conditions. All of the pressure transducers used in this experiment were calibrated. The 0 to 10-psid differential pressure transducers used have an accuracy of $0.21 \%$ of full scale. The 0 to 50 -psig-gauge pressure transducers used have an accuracy of $0.25 \%$ of full scale. The flow meter was accurate to within $2 \%$ of reading. At least 30 data points were recorded for each steady-state condition to obtain a good average value. The uncertainty of the measurements was evaluated by taking into account the instrument accuracy and the data scatter.

Tests were run in several different temperature ranges. The nominal APT operating temperature is $\sim 70^{\circ} \mathrm{C}$. Most tests were run with temperatures in this range. Temperatures varied by as much as $12^{\circ} \mathrm{C}$ over the course of the day because of pump heating. Some tests were run without preheating the loop water. The temperatures during those tests were generally near $40^{\circ} \mathrm{C}$. The temperature did not vary by more than one degree centigrade for any single steady-state data point.

The experimental results for the rod-bundle friction losses will be given first. Then the results for the entire bundle assembly pressure drop will be given.

Table 6. Exit support-plate specifications.

\begin{tabular}{|l|c|l|l|}
\hline Term & $\begin{array}{c}\text { Ladder 2 } \\
\text { without Fillers }\end{array}$ & $\begin{array}{c}\text { Ladder 2 } \\
\text { with Fillers }\end{array}$ & Ladder 10 \\
\hline$A_{I}\left(\mathrm{~m}^{2}\right)$ & 0.0004056 & 0.0003873 & 0.0009772 \\
\hline$A_{0}\left(\mathrm{~m}^{2}\right)$ & 0.0003272 & 0.0003272 & 0.0006545 \\
\hline$A_{0},\left(\mathrm{~m}^{2}\right)$ & 0.0002385 & 0.0002385 & 0.0004912 \\
\hline$A_{2}\left(\mathrm{~m}^{2}\right)$ & 0.001036 & 0.001036 & 0.003776 \\
\hline$l D$ & 1.9355 & 1.9355 & 1.9355 \\
\hline
\end{tabular}




\subsection{Rod Bundle}

This section will focus on the pressure loss between the two pressure taps at opposite ends of the rod bundle itself. The pressure taps were located $0.0345 \mathrm{~m}$ (1.359 in.) after the front support plate and $0.0127 \mathrm{~m}(0.5 \mathrm{in}$.) in front of the rear support plate. The length of the rod bundle between the pressure taps was $0.1743 \mathrm{~m}(6.862 \mathrm{in}$.). This yields $1 / \mathrm{D}_{\mathrm{h}}=100.46$ for the rod bundles without fillers, $1 / \mathrm{D}_{\mathrm{h}}=106.43$ for the rod bundle with fillers, and $1 / \mathrm{D}_{\mathrm{h}}=87.41$ for the large rod bundle from ladder 10 . There is no change in the average fluid velocity and no form losses between the pressure taps; therefore, the only pressure drop is due to frictional losses. Equation 18 is the energy equation between the pressure taps in the rod bundle:

$$
\frac{\Delta \mathrm{P}}{\rho}=\left(f \frac{l}{D_{h}}\right)_{R B} \frac{\mathrm{V}_{R B}{ }^{2}}{2} .
$$

The friction factor (f) will be plotted as a function of Re for the rod bundle. Rearranging Eq. 18 yields the friction factor for the rod bundle as

$$
f=\frac{D_{h}}{l} \frac{\Delta \mathrm{P}}{\rho\left(\frac{\mathrm{V}_{R B}{ }^{2}}{2}\right)} .
$$

The experimental data will be plotted using Eq. 19 vs Re. The analytical values will be derived from Eqs. 8 through 16. Figure 8 compares the experimental data for the three rod bundles from ladder 2 without fillers and ladder 2 with fillers to the analytical values derived from Eqs. 8 through 16. The experimental values with the RHR (residual heat removal) labels were run near the RHR flow range. Figure 9 shows that the analysis matched the experimental data very well.

Recall from Table 5 that the Reynolds number for fully turbulent flow for the ladder-2 pitch-to-diameter ratio was $\operatorname{Re}_{\mathrm{T}}=13,110$. Because the experimental data match the analysis quite well, it should be inferred that the flow is in the transition between laminar and turbulent for $\operatorname{Re}<13,110$. The design Reynolds numbers for this size of rod bundle (for the $1700-\mathrm{MeV}, 100-\mathrm{mA}$ design) range from $\mathrm{Re}=19,427$ for ladder 2 to $\operatorname{Re}=14,228$ for ladder 3 . Therefore, the first four ladders can be assumed to be fully turbulent at their design Reynolds numbers.

The rod bundle with fillers from ladder 2 has the same pitch-to-diameter ratio as the bundles without fillers. This implies that the analytical solution will be very similar to that for the bundles without fillers. The slight change in the subchannel analysis, taking the fillers into account, does not change the plot of the analytical solution significantly. Only subchannel $\mathrm{C}$ is changed in Fig. 6 by the addition of fillers. Therefore, the analytical solution for the rod bundle with fillers is not shown in Fig. 9. The experimental data plotted from Eq. 19 are slightly changed because of a change in the hydraulic diameter and flow area and consequently in the velocity. It is apparent that the fillers have very little effect on the pressure losses within the rod bundle. 


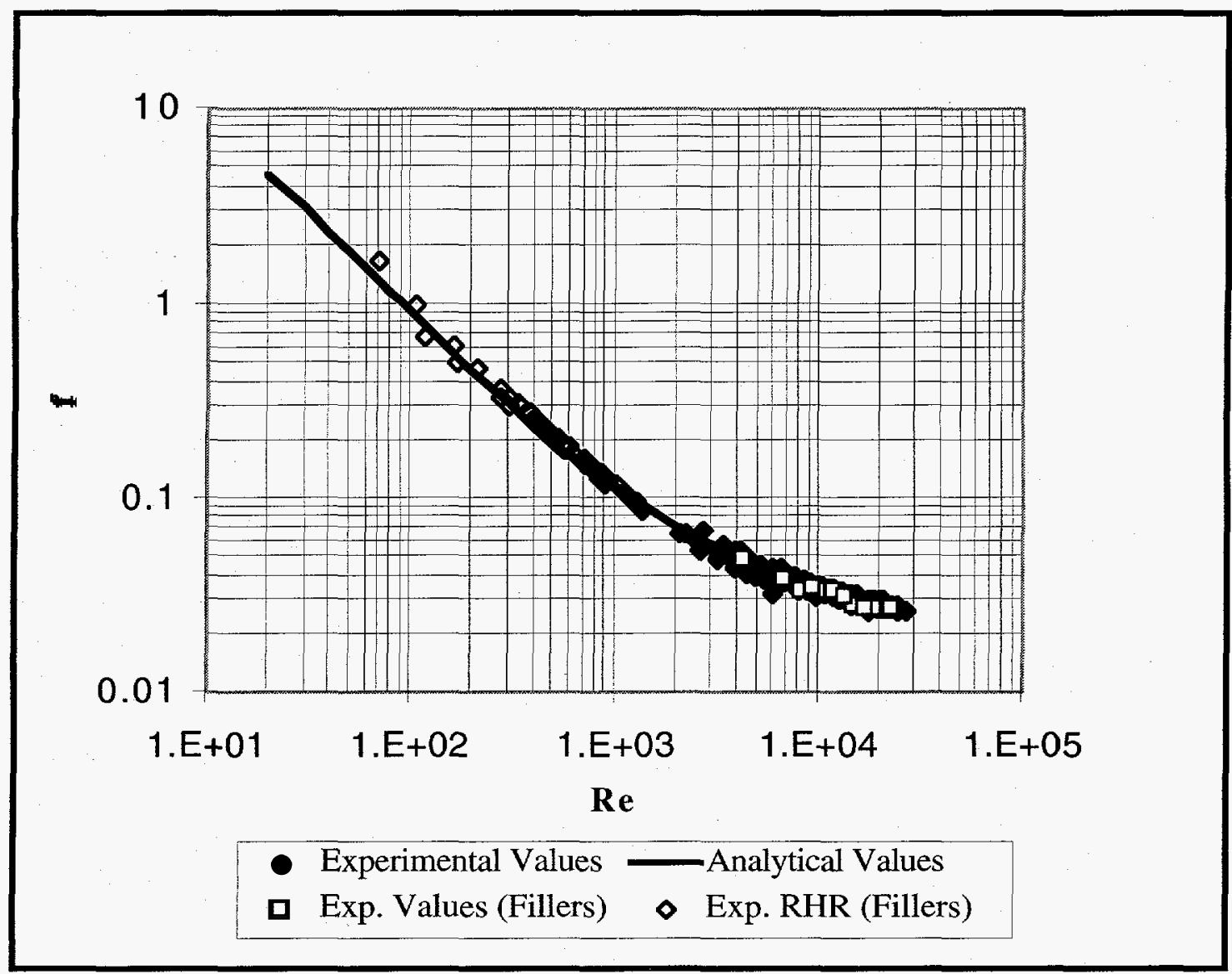

Fig. $9 \quad$ Friction factor for bundle 2.

The data from the larger rod bundle (ladder 10) are plotted in Fig. 10, along with the corresponding analytical values calculated from Eqs. 8 through 16 . Recall that the coefficients of friction for both laminar and turbulent flow are given by different formulas for pitch-to-diameter ratios of $\mathrm{P} / \mathrm{D}<1.1$. Refer to Table 5 for the numerical values of the coefficients of friction for laminar and turbulent flow. The Reynolds number for fully turbulent flow for the ladder-10 rod bundle was $\operatorname{Re}_{\mathrm{T}}=11,140$. There was only one experimental data point above $\mathrm{Re}_{\mathrm{T}}$. The design Reynolds number for this size of rod bundle (for the $1700-\mathrm{MeV}, 100-\mathrm{mA}$ design) was $\mathrm{Re}=7512$. This implies that ladders 9 and 10 will not be fully turbulent at their design Reynolds numbers and most likely will have laminar flow in the small gaps between rods.

Table 5 yields some insight into why the analytical solution for ladder 10 does not match the experimental values as well as the analytical solution for ladder 2 . Ladder 10 has a tightly packed bundle with a pitch-to-diameter ratio of 1.064 . Ladder 10 also has many subchannels along the outside of the bundle, all of which have a pitch-to-diameter (or wall pitch-to-diameter, W/D) ratio $>1.1$. Therefore, the analytical solution is using one set of curve-fit constants for the internal subchannels and another set of curve-fit constants for the edge subchannels (refer to Table 4). These curve-fit constants came from two completely different sets of experimental data in Cheng and Todreas (1986). Therefore, there is no true analytical solution for this particular geometry. 


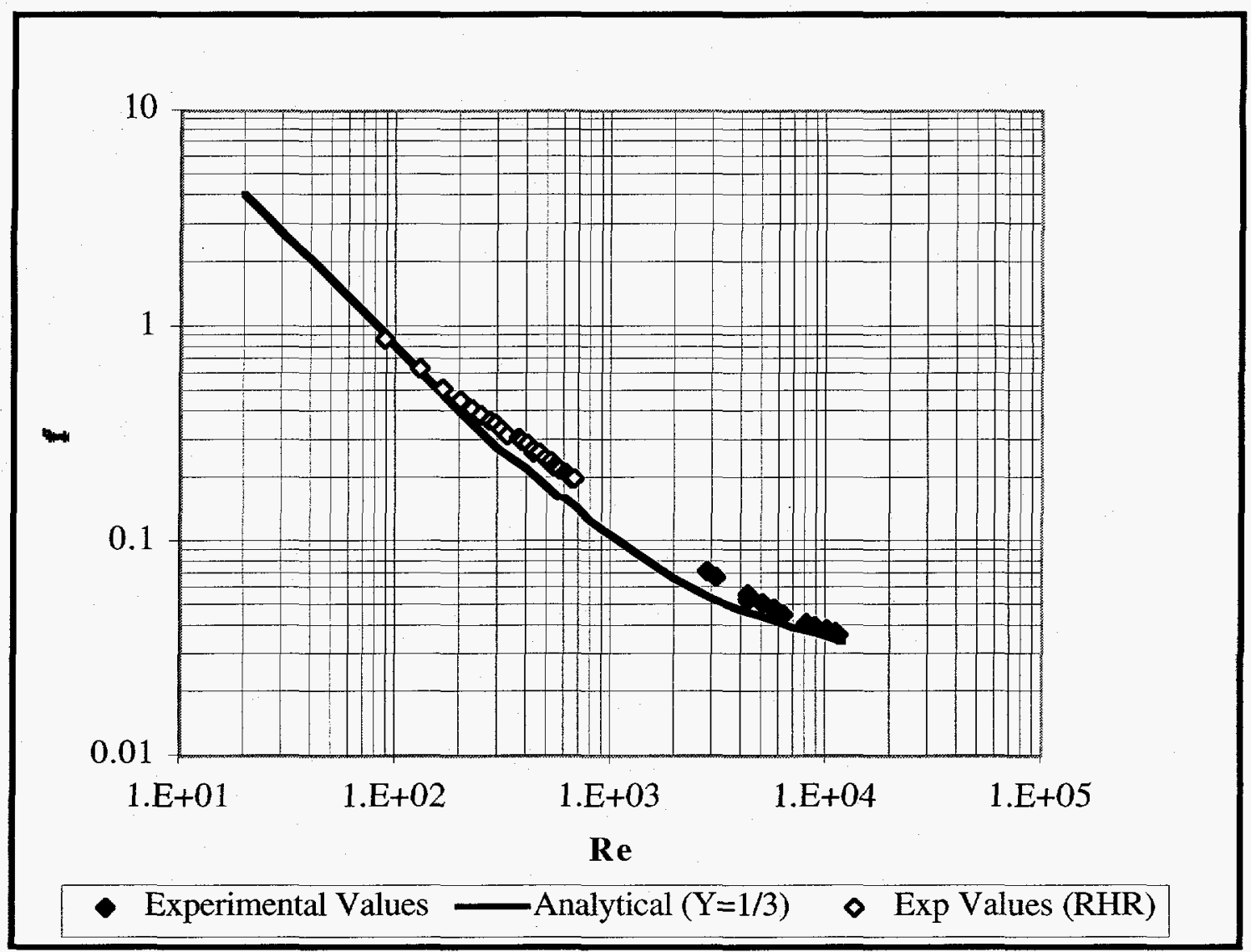

Fig. 10 Friction factor for ladder 10 .

The ladder-10 analytical solution shows another interesting observation. The flow splits for the ladder-10 subchannels in Table 5 show that the internal subchannels velocity is less than half the bundle average velocity. This is significantly worse than the ladder- 2 internal subchannel, where the velocity was $\sim 81 \%$ of the bundle average.

\subsection{Overall Pressure Drop}

The overall pressure drop through the rod bundle can be determined from the sum of the analysis of the front support plate, rod bundle, and rear support plate. Eq. 20:

The energy equation between the downcomer and riser pressure taps is given as

$$
\begin{gathered}
\frac{\Delta \mathrm{P}}{\rho}=\left(K+f \frac{l}{D_{h}}\right) \frac{\mathrm{V}_{\mathrm{OC}}^{2}}{2}+\left(K_{\mathrm{SP}}\right)_{\mathrm{Front}} \frac{\mathrm{V}_{\mathrm{O}}^{2}}{2}+\left(f \frac{l}{D_{h}}\right)_{\mathrm{RB}} \frac{\mathrm{V}_{\mathrm{RB}}^{2}}{2} \\
+\left(K_{\mathrm{SP}}\right)_{\text {Rear }} \frac{\mathrm{V}_{\mathrm{O}}^{2}}{2}+\left(K+f \frac{l}{D_{h}}\right) \frac{\mathrm{V}_{\mathrm{OC}}^{2}}{2}
\end{gathered}
$$

The subscript "OC" refers to the open channel upstream and downstream of the support plates. The open channel is evaluated as a circular smooth pipe. The friction factor 
in the open channel $(f)$ is evaluated from Eq. 4 for $\operatorname{Re}>2200$ and from $f=64 / \operatorname{Re}$ for $\operatorname{Re}<2200$. The form loss for the bend at the rung entrance and exit $K_{O C}$ and the $V D_{h}$ for the open channel are given in Table 7 for all three cases tested. It was determined that the velocity in the front plate is slow enough that the value of the form loss used in the bend affects only the third significant figure in the overall rung pressure loss.

The subscript "Front" refers to the front support plate; the same is applicable for the subscript "Rear". The form loss for the front and rear support plates was derived in Secs. 3.1 and 3.3, respectively. Table 7 gives the equation numbers for evaluating these form losses.

The subscript "RB" refers to the rod bundle. It has already been shown that the analytical values of the frictional losses in the rod bundle match the experimental values very well for the ladder- 2 data and not as well for the ladder-10 data. The analysis for evaluating the friction factor was derived in Section 3.2 and was used in Section 4.1, with the exception of the length of the rod bundle. The entire rod-bundle length was evaluated rather than only the length between the pressure taps. The $l / D_{h}$ for the entire length of rod bundle is given in Table 7 .

The experimental data for ladder 2 are compared to the analytical solution from Eq. 20 in Fig. 11. Equation 20 was rearranged for the plot in Fig. 10 to have the form of an effective form-loss coefficient and was based on the rod-bundle velocity and the rodbundle Reynolds number. The effective form-loss coefficient for the entire rod-bundle assembly is defined in Eq. 21 as

$$
K_{\mathrm{eff}}=\frac{\Delta \mathrm{P}}{\rho} * \frac{2}{\mathrm{~V}_{\mathrm{RB}}^{2}}
$$

The analytical solution for ladder 2 presented in Fig. 11 matched the experimental data. The Reynolds number experimental uncertainty was $5.6 \%$ of the reading, and the form-loss coefficient was $8.5 \%$ of the reading. The analytical solution for the rod bundle alone was shown to be accurate in Sec. 4.1, and Fig. 10 indicates that the analysis for the front and rear support plates also was accurate.

Table 7. Parameters used in Eq. 20.

\begin{tabular}{|l|c|c|c|}
\hline \multicolumn{1}{|c|}{ Term } & Ladder 2 (No Fillers) & Ladder 2 (Fillers) & Ladder 10 \\
\hline$K_{\mathrm{OC} \text { Front }}$ & 0.5 & 0.5 & 0.5 \\
\hline$K_{\mathrm{OC} \mathrm{Rear}}$ & 0.565 & 0.565 & 0.565 \\
\hline$\left(l / D_{h}\right)_{\mathrm{OC}}$ & 2.27 & 2.27 & 1.19 \\
\hline$f_{\mathrm{OC}}$ & Eq. 4 & Eq. 4 & Eq. 4 \\
\hline$K_{\text {SP Front }}$ & Eqs. 3-7 & Eqs. 3-7 & Eqs. 3-7 \\
\hline$K_{\mathrm{SP} \text { Rear }}$ & Eq. 17 & Eq. 17 & Eq. 17 \\
\hline$f_{\mathrm{RB}}$ & Eqs. $8-16$ & Eqs. $8-16$ & Eqs. $8-16$ \\
\hline$\left(l / D_{h}\right)_{\mathrm{RB}}$ & 126.8 & 134.34 & 110.33 \\
\hline
\end{tabular}




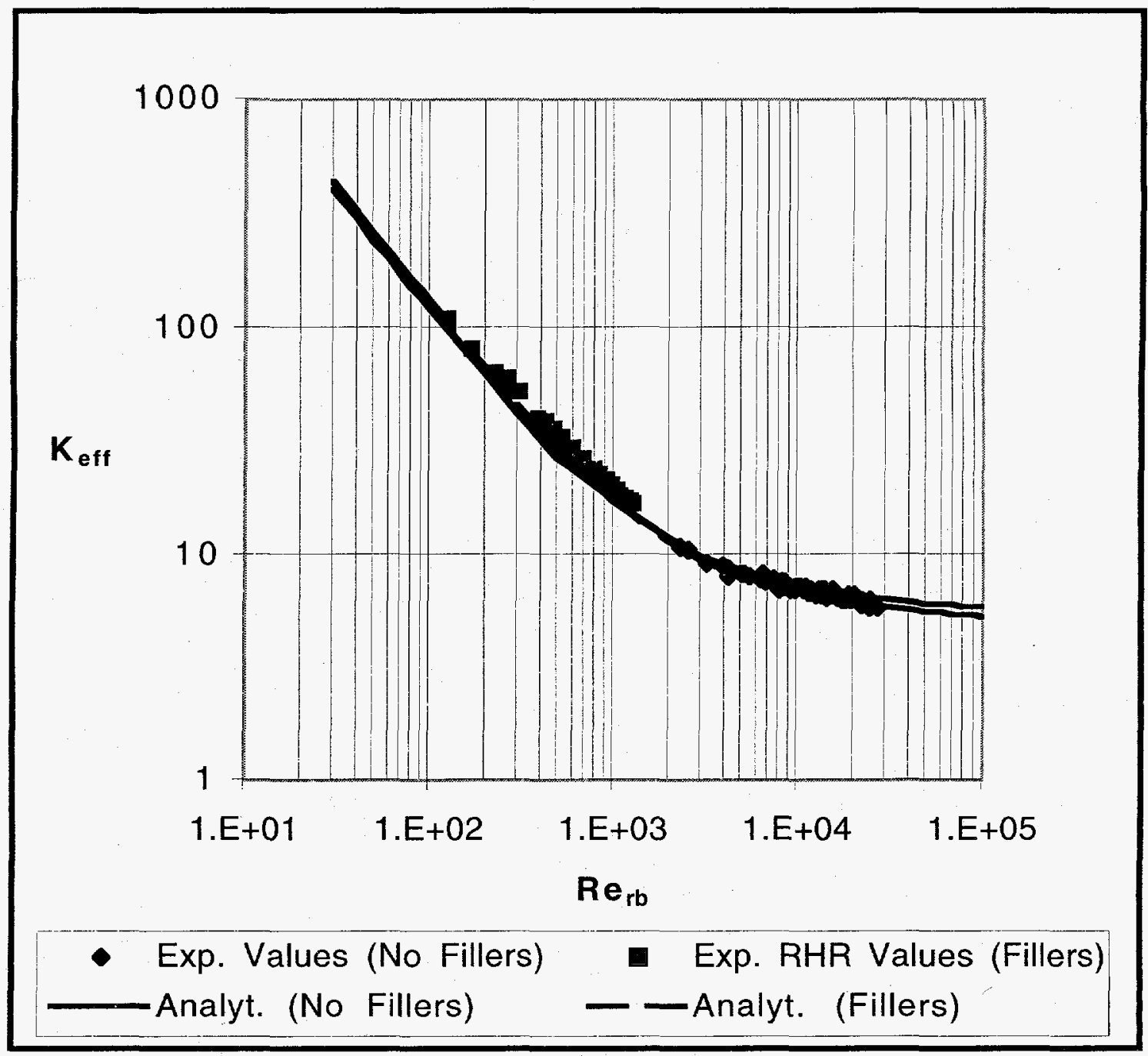

Fig. 11 Ladder-2 overall rung effective form-loss coefficient.

The experimental data for ladder 10 are compared to the analytical solution from Eqs. 20 and 21, as shown in Fig. 12. The analytical solution from Eq. 20 was based on the rod-bundle velocity and the rod-bundle Reynolds number, which is similar to the ladder-2 data.

Figure 11 indicates that the analytical solution for the ladder-10 rod bundle was not an accurate representation. This could have been expected because the analytical solution for the rod bundle alone did not match the experimental data.

\section{CONCLUSIONS}

This paper has shown the results of hydraulic experiments on two of the APT rodbundle geometries. The analytical solution for the rod bundle alone, given by Cheng and Todreas (1986), was shown to match the experimental values for the ladder-2 rod bundle but did not match the experimental values for the ladder-10 rod bundle. A subchannel analysis revealed that the ladder- 2 internal subchannel velocity was between $80 \%$ and 


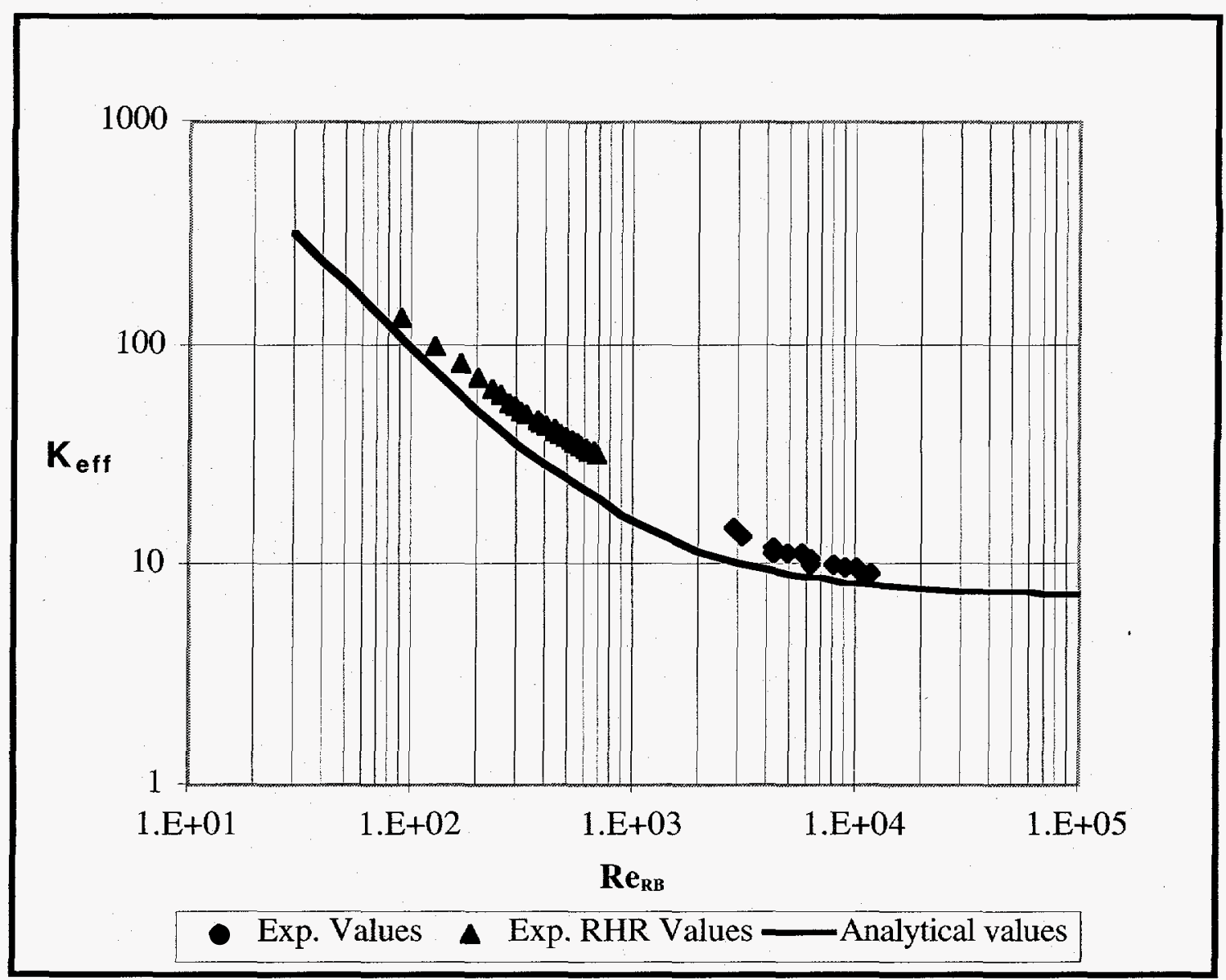

Fig. 12 Ladder-10 overall rung effective form-loss coefficient.

$100 \%$ of the bundle average velocity, whereas the ladder-10 internal subchannel velocity was between $43 \%$ and $79 \%$ of the bundle average velocity. The direct application of the analytical solutions obtained from Cheng and Todreas (1986) was complicated by the complex subchannel geometries at the outer edge of the APT rod bundles. There was little variation in the experimental and analytical hydraulic results caused by the addition of the fillers at the outer sleeve wall. There was also little variation in the experimental results between the three rod bundles tested without fillers.

The variation between the ladder-10 experimental values and the analytical solution shows the need for a better understanding of the flow distribution in the rod bundles. The analysis in Cheng and Todreas (1986) used empirical correlations from triangular-pitch rod bundles in a hexagonal enclosure. The APT geometry is complicated by a circular housing, small rods around the edge of the bundle, and fillers to reduce the subchannels at the housing wall. Cheng and Todreas (1986) also indicated that the flow distribution varies with the Reynolds number. Experimental verification of the flow distribution for various rod-bundle geometries and the range of Reynolds numbers is an area open for further research. 


\section{NOMENCLATURE}

\begin{tabular}{|c|c|}
\hline$A$ & Area \\
\hline a & Constants \\
\hline $\mathrm{C}_{\mathrm{f}}$ & Coefficient of friction \\
\hline $\mathrm{c}$ & Constants for coefficient of friction equations \\
\hline$D$ & Diameter \\
\hline $\mathrm{f}$ & Friction factor \\
\hline$K$ & Form-loss coefficient \\
\hline$l$ & Length \\
\hline $\mathrm{m}$ & Reynolds number exponent \\
\hline$P$ & Pitch \\
\hline$\Delta \mathrm{P}$ & Pressure gradient \\
\hline $\operatorname{Re}$ & Reynolds number \\
\hline$S$ & Flow area fraction \\
\hline$V$ & Velocity \\
\hline$W$ & Wall gap pitch \\
\hline$X$ & Flow split parameter \\
\hline$\beta$ & Multiplier to the form-loss coefficient for $30<\operatorname{Re}<104$ \\
\hline$\gamma$ & Exponent for transition friction factor \\
\hline$v$ & Kinematic viscosity \\
\hline$\rho$ & Density \\
\hline$\tau$ & $\begin{array}{l}\text { Correction factor to form-loss equation to account for the lack of fully } \\
\text { developed flow, Eq. } 2\end{array}$ \\
\hline$\omega$ & Measurement uncertainty \\
\hline$\Psi$ & Intermittency factor, Eq. 15 \\
\hline
\end{tabular}

\section{SUBSCRIPTS}

bL Bundle average, laminar

bT Bundle average, turbulent

Design Nominal baseline value at the time this experiment was performed

eff Effective form-loss coefficient

f Friction

Front $\quad$ Front support plate (upstream support plate) 
h Hydraulic diameter

L Laminar

O Orifice diameter

O' Reduced orifice diameter due to rod protrusion

OC Open channel upstream (or downstream) of support plate

RB Rod bundle

Rear Rear support plate (downstream support plate)

SP Support plate

T Turbulent

$\operatorname{Tr} \quad$ Transition between laminar and turbulent

$\phi \quad$ Additive form-loss coefficient for $30<\operatorname{Re}<104$

$0, \operatorname{Re} \quad$ Multiplication factor to turbulent form-loss coefficient for $30<\operatorname{Re}<$ 104

$0(\operatorname{Re}>10000) \quad$ Fully turbulent form-loss coefficient

$1 \quad$ Upstream fluid area and velocity

$2 \quad$ Downstream fluid area and velocity

\section{ACKNOWLEDGMENTS}

This experimental work would not have been possible without the support of the designers and technicians working on this project at LANL. The designers, Leo Sanchez and J. Tom Sena, perform outstanding work and deserve recognition for a job well done. The following technicians (in alphabetical order) were instrumental in assembling the test section, installing instrumentation, and collecting data: Mike Elder, Brent Faulkner, Robert Ortega, and Jerry Taylor. I would also like to express my sincere appreciation to Keith Woloshun. Keith was the team leader that put all the people and equipment together to get the job done.

In general, experimental work is very expensive when all the hardware, instrumentation, and personnel are added up. Everyone involved in this experiment thank Mike Cappiello, of the APT Project Office, for funding the work.

\section{REFERENCES}

Lisowski, P., Conceptual design report, Los Alamos National Laboratory Report, LA-UR97-1329, April 1997.

Cheng, S-K. and Todreas, N. E., 1986. Hydrodynamic models and correlations for bare and wire-wrapped hexagonal rod bundles - bundle friction factors, subchannel friction factors and mixing parameters. Nucl. Eng. Des. 92, 227-251.

Idelchik, I. E., 1994. Handbook of Hydraulic Resistance, 3rd Edition, CRC Press, Boca Raton, Florida, pp. 189-227. 